\title{
Exploring fungal biodiversity: organic acid production by 66 strains of filamentous fungi
}

Nadège Liaud ${ }^{1,2,3}$, Christian Giniés ${ }^{4,5,6}$, David Navarro ${ }^{1,2,7}$, Nicolas Fabre 3 , Sylvaine Crapart ${ }^{3}$, Isabelle Herpoël- Gimbert ${ }^{1,2}$, Anthony Levasseur ${ }^{1,2}$, Sana Raouche ${ }^{1,2,8^{*}}$ and Jean-Claude Sigoillot ${ }^{1,2}$

\begin{abstract}
Background: Filamentous fungi are well known for their ability to degrade lignocellulosic biomass and have a natural ability to convert certain products of biomass degradation, for example glucose, into various organic acids. Organic acids are suggested to give a competitive advantage to filamentous fungi over other organisms by decreasing the ambient pH. They also have an impact on the ecosystem by enhancing weathering and metal detoxification. Commercially, organic acids can be used as chemical intermediates or as synthons for the production of biodegradable polymers which could replace petroleum-based or synthetic chemicals. One of the advantages of filamentous fungi as biotechnological production platforms for synthetic biology is their ability to degrade vegetal biomass, which is a promising feedstock for the biotechnological production of organic acids. The Fungal Culture Collection of the International Centre of Microbial Resources (CIRM-CF), curated by our laboratory, contains more than 1600 strains of filamentous fungi, mainly Basidiomycetes and Ascomycetes. The natural biodiversity found in this collection is wide, with strains collected from around the world in different climatic conditions. This collection is mainly studied to unravel the arsenal of secreted lignocellulolytic enzymes available to the fungi in order to enhance biomass degradation. While the fungal biodiversity is a tremendous reservoir for "green" molecules production, its potentiality for organic acids production is not completely known.
\end{abstract}

Results: In this study, we screened 40 strains of Ascomycota and 26 strains of Basidiomycota, representing the distribution of fungal diversity of the CIRM-CF collection, in order to evaluate their potential for organic acid and ethanol production, in a glucose liquid medium. We observed that most of the filamentous fungi are able to grow and acidify the medium. We were also able to discriminate two groups of filamentous fungi considering their organic acid production at day 6 of incubation. This first group represented fungi co-producing a wide variety of organic acids and ethanol at concentrations up to $4 \mathrm{~g} \cdot \mathrm{L}^{-1}$ and was composed of all the Aspergilli and only 3 other Ascomycota. The second group was composed of the remaining Ascomycota and all the Basidiomycota which produced mainly ethanol. Among the Basidiomycota, two strains produced oxalic acid and one strain produced gluconic and formic acid. Six strains of Aspergillus producing high concentrations of oxalic, citric and gluconic acids, and ethanol were selected for metabolism analysis.

Conclusion: These results illustrate the versatility in metabolites production among the fungal kingdom. Moreover, we found that some of the studied strains have good predispositions to produce valuable molecules. These strains could be of great interest in the study of metabolism and may represent new models for synthetic biology or consolidated bioprocessing of biomass.

Keywords: Low molecular weight organic acids, Ethanol, Filamentous fungi, Ascomycota, Basidiomycota, Biodiversity

\footnotetext{
* Correspondence: sana.raouche@univ-amu.fr

${ }^{1}$ INRA, UMR1163 Biotechnology of Filamentous Fungi, Marseille F-13288,

France

${ }^{2}$ Aix Marseille Université, UMR1163 Biotechnology of Filamentous Fungi,

Marseille F-13288, France

Full list of author information is available at the end of the article
}

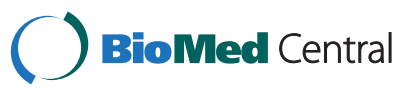

(c) 2014 Liaud et al.; licensee BioMed Central Ltd. This is an Open Access article distributed under the terms of the Creative Commons Attribution License (http://creativecommons.org/licenses/by/4.0), which permits unrestricted use, distribution, and reproduction in any medium, provided the original work is properly credited. The Creative Commons Public Domain Dedication waiver (http://creativecommons.org/publicdomain/zero/1.0/) applies to the data made available in this article, unless otherwise stated. 


\section{Background}

Low molecular weight organic acids production by filamentous fungi, have attracted considerable attention for their role in natural ecology and their potential industrial applications $[1,2]$. Fungal natural production of organic acids is thought to have many key roles in nature depending on the type of fungi producing them. These roles are either due to the $\mathrm{pH}$ decrease consecutive to their secretion or to direct interaction of the organic acid with the environment $[3,4]$. The consecutive decrease in $\mathrm{pH}$ upon their secretion may give a competitive advantage to the acid-tolerant filamentous fungi. For ectomycorrhizal fungi, this $\mathrm{pH}$ decrease also has been suggested to solubilize soil minerals thus releasing nutrient ions for uptake by plants and microorganisms, enhancing mineral weathering [1]. For saprophytic and wood-decaying fungi, this $\mathrm{pH}$ acidification, caused by oxalic acid production, leads to an acid-catalyzed hydrolysis of holocellulose [5-7]. Concerning their direct interaction with the environment, organic acids participate in metal detoxification by metal complexion and oxalic acid plays a major role in biomass degradation [4]. For this reason, Basidiomycota have been extensively studied for their ability to produce oxalic acid [8-12]. To better understand their role in the ecosystem, these studies have focused on plant/fungi symbiosis [9,13], or growth on complex substrates [12,14-16], and are often focused on wood-decay or mycorrhizal fungal species.

In addressing the demand for sustainable alternatives to fossil fuel as a source of energy and chemicals, synthetic biology focuses on understanding how biological systems work and how to use them to benefit society. Organic acids can have multiple industrial applications as food additives, pharmaceutical and cosmetic excipients [17]. They are fully degradable molecules and can be used as chemical intermediates or as synthons for the production of biodegradable polymers, potentially replacing petroleum-based or synthetic chemicals [17]. Some fungi are well known for their natural capability to produce high amounts of various useful organic acids. These fungi are mostly from the Aspergillus (e.g. citric, gluconic, malic and itaconic acids) and Rhizopus genera (e.g. lactic and fumaric acids). Some of these organic acids (i.e. citric acid) can be produced through largescale bioprocesses, showing the high potential of fungi as organic acid production plateforms $[2,18]$.

The literature concerning organic acid production in filamentous fungi often focuses on one specific organic acid and there is little information about the other metabolite produced. In many cases these studies focus on specific strains and cultures are carried out in different conditions and with different complex media. Therefore, it is sometimes difficult to compare the potentiality of filamentous fungi from the literature. Moreover, the fungal biodiversity is estimated to be 1.5 million species [19] and there is still a lot to learn about their potential for metabolite production. In this study, 66 strains of saprophytic and wood-decay fungi (40 Ascomycota and 26 Basidiomycota) were selected and studied in liquid glucose medium, without $\mathrm{pH}$ regulation, in order to compare their metabolic features. These strains belong to 47 different species, representing 23 fungal families. The majority of the strains tested were collected in situ from different geographical areas such as tropical forests from French overseas territories and temperate forests from metropolitan France [19]. Fungal growth and metabolites production was done in glucose liquid media without any $\mathrm{pH}$ regulation to take into account industrial up- and down-stream technical and economical issues. These conditions, close to industrial ones, were chosen to highlight the potential of these organisms for industrial organic acid production. The great diversity and origin of the selected strains enable us to compare the potentiality of a number of fungal groups for the production of organic acids and ethanol.

\section{Results and discussion}

\section{Growth of the selected strains and $\mathrm{pH}$ of the medium}

All the Ascomycota were able to grow in the liquid medium at an initial $\mathrm{pH}$ of 5.5. However, 4 strains of Basidiomycota: Ischoderma benzoinum (BRFM1133), Grifola frondosa (BRFM1162), Panellus serotinus (BRFM1284), and Polyporus squamosus (BRFM1531), did not grow to a sufficient level and did not acidify the medium. These strains were not considered for the following steps. The $\mathrm{pH}$ of the medium was acidified for most of the cultures but to different extents. An extreme acidification, to $\mathrm{pH}$ below or equal to 2, was observed for 33 Ascomycota strains, representing $80 \%$ of the strains from this phylum. In particular, all the Aspergilli tested (22 strains) acidified the medium below pH 2 (Figure 1). Five strains of Ascomycota acidified the medium to $\mathrm{pH}$ between 2 and 4 and only two strains did not or slightly acidify the medium. To the contrary, only two Basidiomycota highly acidified the medium to $\mathrm{pH}$ below or equal to 2 , namely Phanerochaete chrysosporium (BRFM413) and Trametes menziesii (BRFM1281). Eight strains acidified the medium between 2 and 4, and 12 strains did not or slightly acidified the medium (Figure 1). For the strains acidifying the medium, the acidification started within 24 hours of growth and the final $\mathrm{pH}$ was already observed after 3 days of growth.

\section{Organic acid and ethanol production}

HPLC analysis of the supernatants obtained at day 3 of incubation contained only oxalic, malic, propionic and citric acids, found mostly in the supernatants of Aspergillus species. The samples taken at day 6 of incubation showed a better view of the potentiality of the strains tested for 


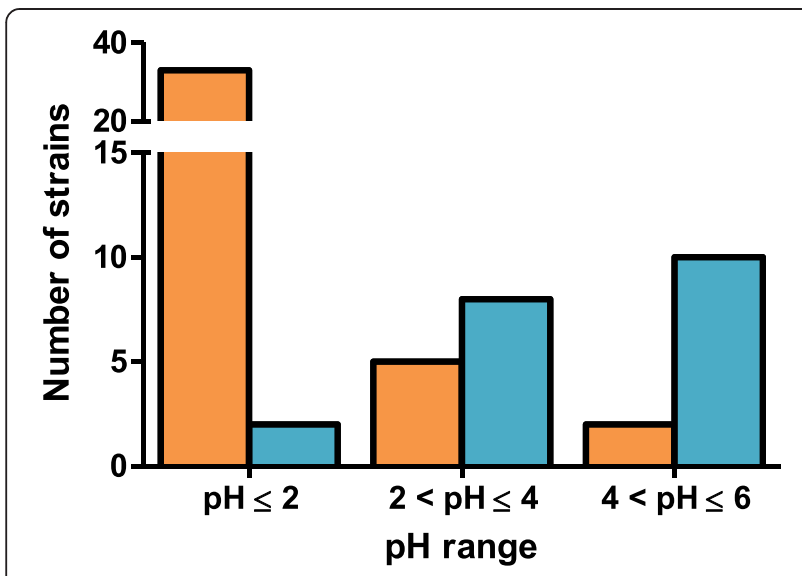

Figure 1 Repartition of Ascomycota and Basidiomycota strains according to the final $\mathrm{pH}$ of growth medium after 6 days of incubation. (orange square) Ascomycota, (sky blue square) Basidiomycota.

organic acid production and allowed the detection of 15 different carboxylic acids at concentration between 0.1 and 3.7 g.L ${ }^{-1}$ : acetic, ascorbic, butyric, citric, fumaric, formic, oxalic, gluconic, itaconic, isobutyric, lactic, malic, propionic, succinic, and tartaric acids (Figure 2). Ethanol was the main neutral metabolite.

Hierarchical clustering was used to classify the strains producing detectable amounts of organic acids and/or ethanol at day 6 of incubation. The clustering was based on production levels of the most widely detected compounds: butyric, citric, gluconic, malic, oxalic, succinic, tartaric acids and ethanol (Figure 2). Two main groups appeared in this clustering: one group of organic acid and ethanol producers and one group producing mainly ethanol.

In the first group, which was mainly composed of Aspergilli, all the compounds analyzed in our assays were detected. This first group represented fungi coproducing a wide variety of organic acids at relatively high concentrations. Two sub-groups could be observed. The first one was composed of various Aspergilli and Nectria species, with only three $A$. niger species. The second one was composed mostly of $A$. niger species, with the exception of $A$. terreus (BRFM111). These results show that $A$. niger is clearly an exception in the fungal kingdom concerning organic acid production. Organic acid production may also be used along with secondary metabolites in the chemotaxonomy of Aspergilli [21].

The second group was composed of the remaining Ascomycota and Basidiomycota producing mainly ethanol. The metabolite concentrations obtained were lower than for the first group and the variety was narrower since only 6 different organic acids out of 15 were detected (Figure 2). In this second group, two subgroups were observed with strains producing only ethanol and strains

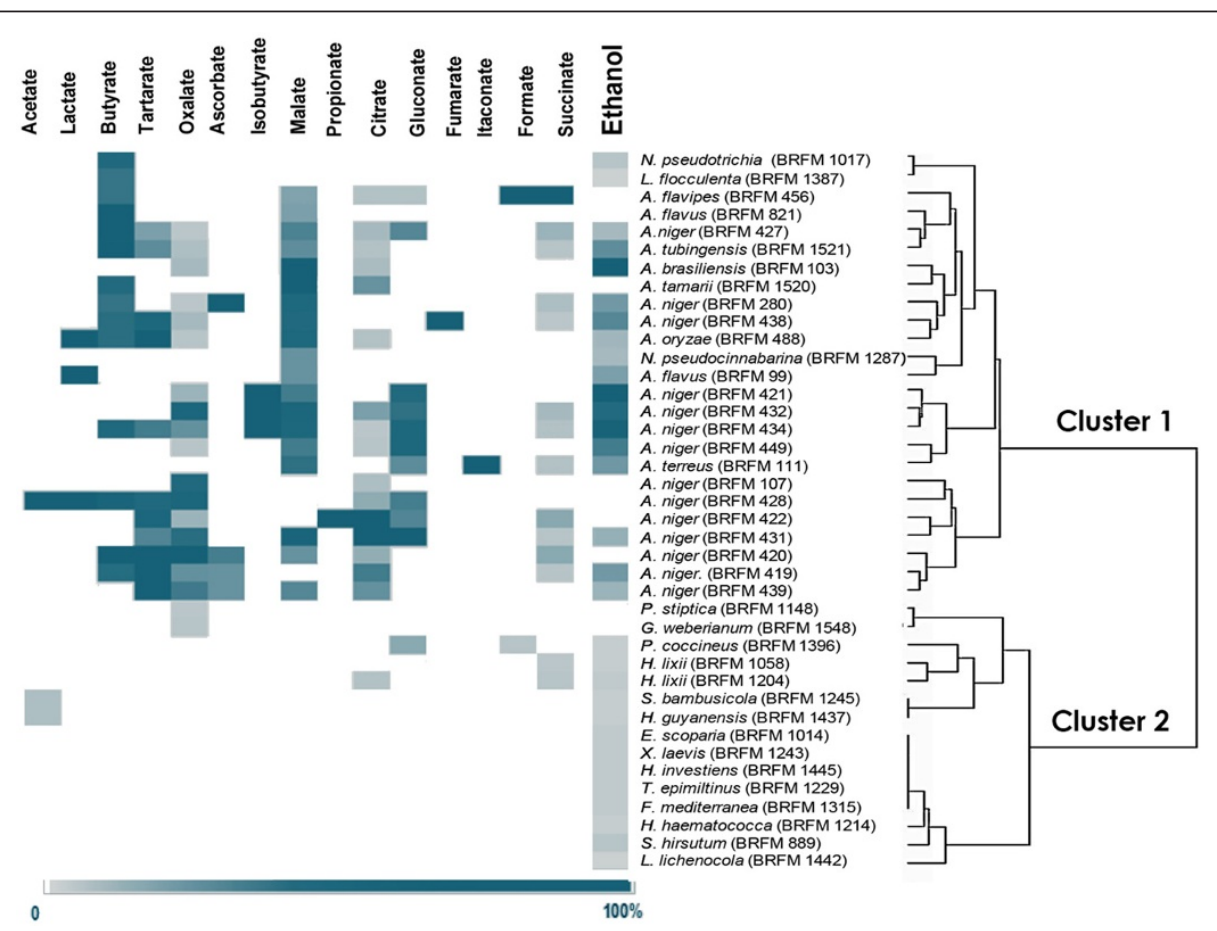

Figure 2 Hierarchical clustering of organic acids and/or ethanol producing strains. Concentration were determined by HPLC-UV or RI analysis and expressed as a percentage of the maximum concentration observed for each metabolite and represented by a color scale with different intensity of blue. Concentration of butyric, tartaric, oxalic, malic, citric, gluconic, succinic acids and ethanol were used to build distance tree. The figure was edited using the Multiexperiment Viewer software [20]. 
producing ethanol and/or other organic acids. Ethanol was detected in 33 strains out of 40 regardless their phylum and species. Although this ethanol production is surprising for organisms traditionally considered as non-fermentative, there are previous records of ethanol production by filamentous fungi. Recent literature shows an increasing interest in ethanol production by filamentous fungi, in particular Flammulina velutipes [22,23]. Some species belonging to Fusarium, Mucor and Paecilomyces were also found to efficiently convert xylose to ethanol with high yields [24-26].

Concerning the relation between $\mathrm{pH}$ acidification (section Growth of the selected strains and $\mathrm{pH}$ of the medium) and organic acid production, as expected most of the highly acidifying strains were good organic acid producers, from the Ascomycota phylum. However, the $\mathrm{pH}$ obtained in the Ascomycota growth media was below 2, which is far below the pKa of organic acids (between 3 and 5). Moreover, some strains for example Phanerochaete chrysosporium (BRFM413) and Cosmospora vilior (BRFM1198) acidified the medium below 3 but did not produce detectable amounts of organic acids. Therefore, the decrease in $\mathrm{pH}$ in our experiments cannot be explained by the sole release of large amount of organic acids. The acidification of the medium is probably mainly due to the removal of the ammonium from ammonium sulfate salt, used as nitrogen source, or excretion of $\mathrm{H}^{+}$ions from the assimilation of $\mathrm{NH}_{4}^{+}$.

\section{Organic acid and ethanol production in the Basidiomycota phylum}

In the Basidiomycota phylum, only 6 strains out of 20 produced organic acids or ethanol. Pycnoporus coccineus (BRFM1396) was the only Basidiomycota producing several metabolites with 0.6 g. $\mathrm{L}^{-1}$ of gluconic acid, 0.2 g. $\mathrm{L}^{-1}$ of formic acid and 0.2 g.L $\mathrm{L}^{-1}$ of ethanol (Figure 2). Stereum hirsutum (BRFM889), Tinctoporellus epimiltinus (BRFM1229) and Fomitiporia mediterranea (BRFM1315) produced only ethanol at concentrations between 0.12 and 0.19 g.L $\mathrm{L}^{-1}$. Two strains: Postia stiptica (brown-rot, BRFM1148) and Ganoderma weberianum (white-rot, BRFM1548) produced only oxalic acid at 0.06 and 0.08 g. $\mathrm{L}^{-1}$, respectively. Generally, oxalic acid is accumulated in large quantities by brown-rot fungi and detected in lower amounts in white-rot fungi $[8,10]$. This difference was attributed to the inability of brown-rot fungi to undertake an active regulation of oxalic acid concentration [10]. The other brown-rot tested, Gloeophyllum sepiarium, produced neither organic acids nor ethanol. Interestingly, $P$. coccineus (white-rot) produced 0.2 g.L $\mathrm{L}^{-1}$ of formic acid. Formic acid production by this strain might be the result of oxalate decarboxylation, as described previously for white-rots [11].

\section{Organic acid and ethanol production in the Ascomycota phylum}

Out of the 40 strains, 6 strains of Ascomycota produced neither organic acids nor ethanol at detectable level: Cosmospora vilior (BRFM982 and BRFM1198), Nectria pseudocinnabarina (BRFM1288), Xylaria schweinitzii (BRFM1447), Hypomyces luteovirens (BRFM1580), and Cordyceps militaris (BRFM1581). Ascorbic, fumaric and itaconic acids were detected in only a few supernatants, all from Aspergilli, and at concentrations below the limit of quantification $\left(0.05\right.$ g. $\left.\mathrm{L}^{-1}\right)$. The maximal metabolite concentrations were all observed in Aspergilli culture media and ranged from 0.1 g.L $\mathrm{L}^{-1}$ for lactic and tartaric acids to more than 2 g. $\mathrm{L}^{-1}$ for citric, formic, gluconic acids and ethanol (Table 1). Indeed, among the fungal kingdom, Aspergilli are well known for their ability to accumulate large amounts of organic acids [2,18]. In our culture conditions the concentration obtained were low compared to the literature where the conversion of glucose into organic acid is described to approach $100 \%$ for some Aspergilli in optimized conditions [2]. This can be explained by the fact that accumulation of organic acid is

Table 1 Highest concentrations of LMWOA and ethanol obtained at day 6 of incubation, for each compound and the corresponding producing strains

\begin{tabular}{lll}
\hline Compound & Fungal strain & g.. $\mathbf{L}^{\mathbf{1}}$ \\
\hline Ethanol & Ascomycota & \\
Gluconic acid & A. niger (BRFM421) & 4.1 \\
Formic acid & A. niger (BRFM431) & 3.7 \\
Citric acid & A. flavipes (BRFM456) & 3.3 \\
Succinic acid & A. niger (BRFM422) & 2.2 \\
Oxalic acid & A. flavipes (BRFM456) & 1.8 \\
Malic acid & A. niger (BRFM420) & 1.6 \\
Acetic acid & A. niger (BRFM103) & 0.6 \\
Propionic acid & A. niger (BRFM428) & 0.4 \\
Butyric acid & A. niger (BRFM422) & 0.2 \\
Isobutyric acid & A. flavus (BRFM821) & 0.2 \\
Tartaric acid & A. niger (BRFM432) & 0.2 \\
Lactic acid & A. niger (BRFM420) & 0.1 \\
Ascorbic acid & A. niger (BRFM428) & 0.1 \\
Fumaric acid & A. niger (BRFM280) & $<0.05^{*}$ \\
Itaconic acid & A. niger (BRFM438) & $<0.05^{*}$ \\
Ethanol & A. terreus (BRFM111) & $<0.05^{*}$ \\
Gluconic acid & Basidiomycota & \\
Oxarmic acid & S. hirsutum BRFM889) & 0.2 \\
\hline P. coccineus (BRFM1396) & 0.6 \\
\hline P. coccineus (BRFM1396) & G. weberianum (BRFM1548) & 0.1 \\
\hline
\end{tabular}

*limit of quantification. 
strongly influenced by the medium composition $[2,18]$. These results show that, in the Aspergillus genus, the major metabolite secreted is different depending on the strain.

Six strains of Aspergillus (BRFM103, BRFM420, BRFM421, BRFM422, BRFM431 and BRFM434) have been selected for further studies due to their high organic acids or ethanol production, and to the variety of organic acids produced. A. brasiliensis BRFM103, A. niger BRFM421, and A. niger BRFM434 were selected for their ability to produce ethanol, 3.6, 4.1, and 2.5 g. $\mathrm{L}^{-1}$, respectively. A. niger BRFM420 was selected for its production of oxalic acid $\left(1.6\right.$ g. $\left.\mathrm{L}^{-1}\right)$. A. niger BRFM422 was selected for its production of citric acid (2.2 g. $\mathrm{L}^{-1}$ ) and A. niger BRFM431 was selected for its production of citric (2.1 g. $\left.\mathrm{L}^{-1}\right)$ and gluconic acids (3.7 g. $\left.\mathrm{L}^{-1}\right)$. At day 6 of incubation 14.2 to 22.9 g.L $\mathrm{L}^{-1}$ of glucose remained in the medium and these strains converted 8 to $15 \%$ of the glucose consumed to the main organic acid or ethanol (Table 2).

In order to confirm the identity of organic acids of applied interest observed by HPLC-UV (i.e. citric, lactic, malic, and oxalic acid), supernatants from fresh cultures of A. brasiliensis BRFM103, A. niger BRFM422 and A. niger BRFM428 were analyzed by GC-MS. These 4 organic acids were detected in all the supernatants. With HPLC-UV, malic acid was not detected in the supernatants of strains BRFM422 and BRFM428, and lactic acid was detected only in BRFM428. This result suggests that these three strains are able to produce citric, lactic, malic and oxalic acid. However, only BRFM103 produced malic acid and BRFM422 produced lactic acid at amounts detectable by HPLC-UV. Besides, we confirm the high ethanol production by BRFM103 and found smaller amounts of ethanol in BRFM422 and BRFM428 as well. This ethanol production was also found by HPLC-RI (data not shown) showing a biological variability compared to the first cultures.

As expected the two main organic acids produced by the 6 Aspergilli strains were citric acid and gluconic acid $[2,18]$. Interestingly, all these strains also produced oxalic acid. For most of them the production of oxalic acid was low and ranged from 0.4 to 0.9 g.. $\mathrm{L}^{-1}$. This is consistent with the literature since oxalic acid production has been shown to be inhibited at $\mathrm{pH}$ below 3 by $A$. niger [27] and by ammonium and excess of substrate $[1,28]$. One exception is $A$. niger BRFM420 which produced 2 g.L $\mathrm{L}^{-1}$ of oxalic and with a conversion yield of $7 \mathrm{~g}$ oxalic acid $/ 100 \mathrm{~g}$ of glucose consumed. For this strain, the only other organic acid detected was citric acid at 0.5 g. $\mathrm{L}^{-1}$. Even if this conversion yield is low compared to yields obtained in optimum conditions [29], this strain is particularly interesting since it seems more disposed than other Aspergilli to produce oxalic
Table 2 Concentrations and conversion yields for the 6 best organic acid producers

\begin{tabular}{|c|c|c|}
\hline & Concentration $\left(\mathrm{g} \cdot \mathrm{L}^{-1}\right)$ & Mean $\mathrm{Y}_{\mathrm{P} / \mathrm{s}}(\%)$ \\
\hline \multicolumn{3}{|c|}{ Aspergillus brasiliensis (BRFM103) } \\
\hline Oxalic acid & $0.4 \pm 0.1$ & 1.2 \\
\hline Citric acid & $0.5 \pm 0.1$ & 1.5 \\
\hline Malic acid & $0.7 \pm 0.2$ & 2.0 \\
\hline Ethanol & $3.9 \pm 1.0$ & 10.8 \\
\hline Residual glucose & $14.2 \pm 1.7$ & \\
\hline \multicolumn{3}{|c|}{ Aspergillus niger (BRFM420) } \\
\hline Oxalic acid & $2.0 \pm 0.4$ & 7.0 \\
\hline Citric acid & $0.5 \pm 0.1$ & 1.9 \\
\hline Residual glucose & $21.6 \pm 3.8$ & \\
\hline \multicolumn{3}{|c|}{ Aspergillus niger (BRFM421) } \\
\hline Oxalic acid & $0.4 \pm 0.1$ & 1.4 \\
\hline Gluconic acid & $2.6 \pm 0.5$ & 9.5 \\
\hline Malic acid & $0.4 \pm 0.1$ & 1.6 \\
\hline Ethanol & $4.0 \pm 0.7$ & 14.5 \\
\hline Residual glucose & $22.9 \pm 1.1$ & \\
\hline \multicolumn{3}{|c|}{ Aspergillus niger (BRFM422) } \\
\hline Oxalic acid & $0.4 \pm 0.1$ & 1.3 \\
\hline Citric acid & $2.5 \pm 0.6$ & 7.7 \\
\hline Tartaric acid & $0.2 \pm 0.1$ & 0.6 \\
\hline Gluconic acid & $3.4 \pm 0.1$ & 10.4 \\
\hline Succinic acid & $0.8 \pm 0.1$ & 2.3 \\
\hline Fumaric acid & $0.7 \pm 0.2$ & 2.3 \\
\hline Residual glucose & $17.6 \pm 1.3$ & \\
\hline
\end{tabular}

Aspergillus niger (BRFM431)

Oxalic acid $\quad 0.9 \pm 0.1 \quad 3$

Citric acid $\quad 2.4 \pm 0.4$

Gluconic acid $\quad 4.7 \pm 0.6 \quad 15.6$

Malic acid $\quad 0.4 \pm 0.1 \quad 1.5$

$\begin{array}{lll}\text { Succinic acid } & 0.7 \pm 0.1 & 2.2\end{array}$

Residual glucose $\quad 20.4 \pm 1.6$

Aspergillus niger (BRFM434)

\begin{tabular}{lll} 
Oxalic acid & $0.6 \pm 0.1$ & 2.2 \\
Citric acid & $0.4 \pm 0.1$ & 1.4 \\
Gluconic acid & $2.4 \pm 0.8$ & 8.5 \\
Ethanol & $2.1 \pm 0.5$ & 7.4 \\
Residual glucose & $21.9 \pm 1.7$ & \\
\hline
\end{tabular}

Yields are expressed in $\mathrm{g}$ of product per $\mathrm{g}$ of glucose consumed. $( \pm S D), n=3$.

acid, even when grown in conditions not promoting the production of this organic acid.

Regarding ethanol production, the best yield, 14.5\%, was observed with A.niger (BRFM421). A. oryzae and Rhizopus oryzae have been shown to convert $51.8 \%$ of 
glucose into ethanol [30]. However, a complex medium was used in this study, therefore glucose was not the sole carbon source. As a comparison, Saccharomyces cerevisiae, the fermentative organism used for industrial ethanol production, has a maximum theorical yield on glucose of $51.1 \%$, and industry processes are considered economically relevant above $90 \%$ of this yield [31]. The main drawback of ethanol production from biomass using Saccharomyces is that the naturally occurring yeast cannot metabolize xylose, a product of biomass degradation [32]. These findings could be of interest for the production of 2 nd generation ethanol from hemicelluloses and consolidated bioprocessing of biomass to ethanol [33].

\section{Methods}

\section{Strains}

All the strains were provided by the fungal culture collection (BRFM) of the International Centre of Microbial Resources (CIRM-CF; http://www6.inra.fr/cirm_eng/cirm-cf, Marseille, France) of the French National Institute for Agricultural Research (INRA, Marseille, France). At least one species from each family represented at the CIRM-CF was selected in order to analyze the available biodiversity. More strains and species were studied for families largely represented in the collection to achieve a better geographic diversity (Table 3, Figure 3). In total, 66 strains from 47 different species representing 23 fungal families were studied for organic acid production and other metabolic end-products. 40 of these strains originated from the Ascomycota phylum and 26 strains originated from the Basidiomycota phylum. Strains were cultivated on malt agar medium for mycelium expansion prior to inoculation of liquid cultures.

\section{Chemicals and reagents}

Ultrapure water (conductivity $18.2 \mathrm{~m} \Omega$ ) was used in all experiments. For fungal cultures, malt extract was purchased from VWR, EDTA- $\mathrm{Na}_{2}$ and glucose were from Sigma, $\left(\mathrm{NH}_{4}\right)_{2} \mathrm{SO}_{4}$ and $\mathrm{CaCl}_{2}$ were from Panreac, $\mathrm{H}_{3} \mathrm{BO}_{3}$, $\mathrm{MnCl}_{2}, \mathrm{FeSO}_{4}, \mathrm{CuSO}_{4}, \mathrm{CoCl}_{2} \mathrm{Na}_{2} \mathrm{MoO}_{4}, \mathrm{MgSO}_{4}, \mathrm{KH}_{2} \mathrm{PO}_{4}$, and $\mathrm{ZnSO}_{4}$ were purchased from Prolabo and Bacto agar was purchased from Fischer.

For analytic methods, $\mathrm{CD}_{3} \mathrm{OH}$, HPLC grade organic acid standards (acetic, adipic acid, L-ascorbic acid, benzoic acid, butyric acid, citric acid, isobutyric acid, formic acid, fumaric acid, L-(+)-lactic acid, DL-isocitric acid trisodium salt hydrate, maleic acid, malonic acid, D(+)-malic acid, oxalic acid, phytic acid, propionic acid, (-)quinic, succinic acid, shikimic acid,D-(-)-tartaric acid), methylchloroformate (MCF), and glucose were purchased from Sigma, HPLC grade ethanol was purchased from Fluka. Dichloromethane was from Carlo Erba Reagents.

\section{Liquid cultures}

The liquid medium was composed of $\left(\mathrm{NH}_{4}\right)_{2} \mathrm{SO}_{4}(8 \mathrm{mM})$, $\mathrm{CaCl}_{2}(1 \mathrm{mM}), \mathrm{KH}_{2} \mathrm{PO}_{4}(11 \mathrm{mM}), \mathrm{MgSO}_{4}(2 \mathrm{mM})$, glucose $5 \%(\mathrm{wt} / \mathrm{vol})$ and trace elements and had an initial $\mathrm{pH}$ of 5.5 . The final concentrations of trace elements was $\mathrm{ZnSO}_{4}$ $(76 \mu \mathrm{M}), \mathrm{H}_{3} \mathrm{BO}_{3}(178 \mu \mathrm{M}), \mathrm{MnCl}_{2}(25 \mu \mathrm{M}), \mathrm{FeSO}_{4}$ $(18 \mu \mathrm{M}), \mathrm{CoCl}_{2}(7.1 \mu \mathrm{M}), \mathrm{CuSO}_{4}(6.4 . \mu \mathrm{M}), \mathrm{Na}_{2} \mathrm{MoO}_{4}$ $(6.2 \mu \mathrm{M})$, and EDTA- $\mathrm{Na}_{2}(174 \mu \mathrm{M})$. The glucose concentration had to be high, in order to be close to industrial conditions for organic acid production in Ascomycota [34]. In previous screenings of Basidiomycota for organic acid production, the glucose concentration was set to 5\% [12]. This concentration was therefore chosen to be suitable for both Ascomycota and Basidiomycota growth. For Basidiomycota, which hardly grow on such media, Tatum vitamins [35] and yeast extract $\left(0.03 \mathrm{~g} . \mathrm{L}^{-1}\right)$ were added to the liquid medium. Cultivations were carried out in $250 \mathrm{~mL}$ baffled flasks to facilitate oxygen transfert. They contained $100 \mathrm{~mL}$ of liquid medium and were incubated for 6 days at $30^{\circ} \mathrm{C}$ in an orbital incubator at 120 and $140 \mathrm{rpm}$ for Ascomycota and Basidiomycota, respectively. For Aspergilli, the liquid medium was inoculated at an initial titer of $2 \times 10^{6}$ spores. $\mathrm{mL}^{-1}$. For other fungi (Basidiomycota and other Ascomycota), that do not produce enough spores in our growth conditions, fungal disks, $4 \mathrm{~mm}$ in diameter, were collected from the solid medium. For each strain, 3 tubes containing 1 fungal disk and $1 \mathrm{~mL}$ sterile water were crushed at a frequency of $4 \mathrm{~s}^{-1}$ during $60 \mathrm{~s}$ using a FastPrep-24 (MPBio, Solon, OH, USA). The 3 tubes were then mixed together. Afterwards, $1 \mathrm{~mL}$ of the inoculum preparation was added to each flask. Cultures were carried out in triplicates.

\section{Analytical methods}

During the incubation, the acidity of the culture media was evaluated daily with $\mathrm{pH}$ paper (Duotest ${ }^{\circ}$, MacheryNagel, Düren, Germany). At days 3 and 6 of incubation, $2 \mathrm{~mL}$ samples were harvested from the media. Mycelium was removed by centrifugation and the supernatant was collected after ultra-filtered using Vivaspin ${ }^{\circ}$ kD (VWR, Strasbourg, France) tubes to remove proteins. The filtrates were analyzed for organic acids by HPLC (Agilent 1100 series HPLC, Santa Clara, CA, USA) using an Aminex HPX-87H organic acid analysis column $(100 \mathrm{~mm} \times$ $7.8 \mathrm{~mm}$, Biorad, Marnes-la-Coquette, France). The column was equilibrated in $2.5 \mathrm{mM} \mathrm{H}_{2} \mathrm{SO}_{4}$ at $35^{\circ} \mathrm{C}$ and samples were eluted with $2.5 \mathrm{mM} \mathrm{H}_{2} \mathrm{SO}_{4}$ at a $0.6 \mathrm{~mL}$. $\mathrm{min}^{-1}$ flow rate. Organic acids were detected with a UV detector at $210 \mathrm{~nm}$ (G1314A, Agilent HPLC 1100 series) and ethanol and glucose were detected with a differential refractometer (HP1047A, Hewlett Packard). Data were acquired with ChemStation software (Agilent, Hewlett Packard, Waldbronn, Germany). The first analysis of metabolite secretion was performed with pools of the three replicates of each strain in order to get an estimation of the 
Table 3 List of the strains studied and their geographic origin and corresponding BRFM numbers

\begin{tabular}{|c|c|c|c|c|}
\hline & Current name & Family & Continent & BRFM \\
\hline \multicolumn{5}{|l|}{ Ascomycota } \\
\hline & Cordyceps militaris & Cordycipitaceae & Europe & 1581 \\
\hline & Eutypella scoparia & Diatrypaceae & Central America & 1014 \\
\hline & Hypocrea lixii & Hypocreaceae & Europe & 1058 \\
\hline & Hypocrea lixii & Hypocreaceae & South America & 1204 \\
\hline & Hypomyces luteovirens & Hypocreaceae & Europe & 1580 \\
\hline & Cosmospora vilior & Nectriaceae & Central America & 982 \\
\hline & Nectria pseudotrichia & Nectriaceae & Central America & 1017 \\
\hline & Cosmospora vilior & Nectriaceae & Europe & 1198 \\
\hline & Haematonectria haematococca & Nectriaceae & South America & 1214 \\
\hline & Nectria pseudocinnabarina & Nectriaceae & South America & 1287 \\
\hline & Nectria pseudocinnabarina & Nectriaceae & Central America & 1288 \\
\hline & Lanatonectria flocculenta & Nectriaceae & South America & 1387 \\
\hline & Haematonectria guyanensis & Nectriaceae & South America & 1437 \\
\hline & Lasionectria lichenocola & Nectriaceae & Europe & 1442 \\
\hline & Sinosphaeria bambusicola & Thyridiaceae & $N A^{*}$ & 1245 \\
\hline & Aspergillus brasiliensis & Trichocomaceae & Europe & 103 \\
\hline & Aspergillus flavipes & Trichocomaceae & Europe & 456 \\
\hline & Aspergillus flavus & Trichocomaceae & NA & 99 \\
\hline & Aspergillus flavus & Trichocomaceae & Africa & 821 \\
\hline & Aspergillus niger & Trichocomaceae & Africa & 107 \\
\hline & Aspergillus niger & Trichocomaceae & NA & 280 \\
\hline & Aspergillus niger & Trichocomaceae & Central America & 419 \\
\hline & Aspergillus niger & Trichocomaceae & Central America & 420 \\
\hline & Aspergillus niger & Trichocomaceae & Central America & 421 \\
\hline & Aspergillus niger & Trichocomaceae & Central America & 422 \\
\hline & Aspergillus niger & Trichocomaceae & Central America & 427 \\
\hline & Aspergillus niger & Trichocomaceae & Central America & 428 \\
\hline & Aspergillus niger & Trichocomaceae & Central America & 431 \\
\hline & Aspergillus niger & Trichocomaceae & Central America & 432 \\
\hline & Aspergillus niger & Trichocomaceae & Central America & 434 \\
\hline & Aspergillus niger & Trichocomaceae & Central America & 438 \\
\hline & Aspergillus niger & Trichocomaceae & Central America & 439 \\
\hline & Aspergillus niger & Trichocomaceae & Europe & 449 \\
\hline & Aspergillus oryzae & Trichocomaceae & Europe & 488 \\
\hline & Aspergillus tamarii & Trichocomaceae & South America & 1520 \\
\hline & Aspergillus terreus & Trichocomaceae & Europe & 111 \\
\hline & Aspergillus tubingensis & Trichocomaceae & South America & 1521 \\
\hline & Xylaria laevis & Xylariaceae & South America & 1243 \\
\hline & Xylaria schweinitzii & Xylariaceae & South America & 1447 \\
\hline & Hypoxylon investiens & Xylariaceae & South America & 1445 \\
\hline \multicolumn{5}{|l|}{ Basidiomycota } \\
\hline & Heterobasidion annosum & Bondarzewiaceae & NA & 238 \\
\hline & Gymnopilus junonius & Cortinariaceae & Europe & 969 \\
\hline
\end{tabular}


Table 3 List of the strains studied and their geographic origin and corresponding BRFM numbers (Continued)

\begin{tabular}{|c|c|c|c|}
\hline Ischnoderma benzoinum & Fomitopsidaceae & Europe & 1133 \\
\hline Postia stiptica & Fomitopsidaceae & Europe & 1148 \\
\hline Amauroderma sp. & Ganodermataceae & South America & 1359 \\
\hline Ganoderma weberianum & Ganodermataceae & South America & 1548 \\
\hline Gloeophyllum sepiarium & Gloeophyllaceae & Europe & 988 \\
\hline Fomitiporia mediterranea & Hymenochaetaceae & Europe & 1315 \\
\hline Dichostereum effuscatum & Lachnocladiaceae & Europe & 91 \\
\hline Lentinula edodes & Marasmiaceae & NA & 353 \\
\hline Grifola frondosa & Meripilaceae & Europe & 1162 \\
\hline Abortiporus biennis & Meruliaceae & Europe & 1215 \\
\hline Omphalotus olearius & Omphalotaceae & Europe & 1195 \\
\hline Phanerochaete chrysosporium & Phanerochaetaceae & Europe & 413 \\
\hline Pleurotus ostreatus & Pleurotaceae & Europe & 1326 \\
\hline Grammothele fuligo & Polyporaceae & South America & 1046 \\
\hline Daedaleopsis confragosa & Polyporaceae & Europe & 1187 \\
\hline Perenniporia ochroleuca & Polyporaceae & Europe & 1192 \\
\hline Earliella scabrosa & Polyporaceae & South America & 1220 \\
\hline Tinctoporellus epimiltinus & Polyporaceae & South America & 1229 \\
\hline Trametes menziesii & Polyporaceae & Oceania & 1281 \\
\hline Trametes sp. & Polyporaceae & South America & 1361 \\
\hline Pycnoporus coccineus & Polyporaceae & Oceania & 1396 \\
\hline Polyporus squamosus & Polyporaceae & Europe & 1531 \\
\hline Stereum hirsutum & Stereaceae & Europe & 889 \\
\hline Panellus serotinus & Tricholomataceae & Europe & 1284 \\
\hline
\end{tabular}

Families are sorted in alphabetical order, when several strains from one family were tested; species were sorted in alphabetical order and by increasing BRFM number for strains from the same species.

*NA: not available.

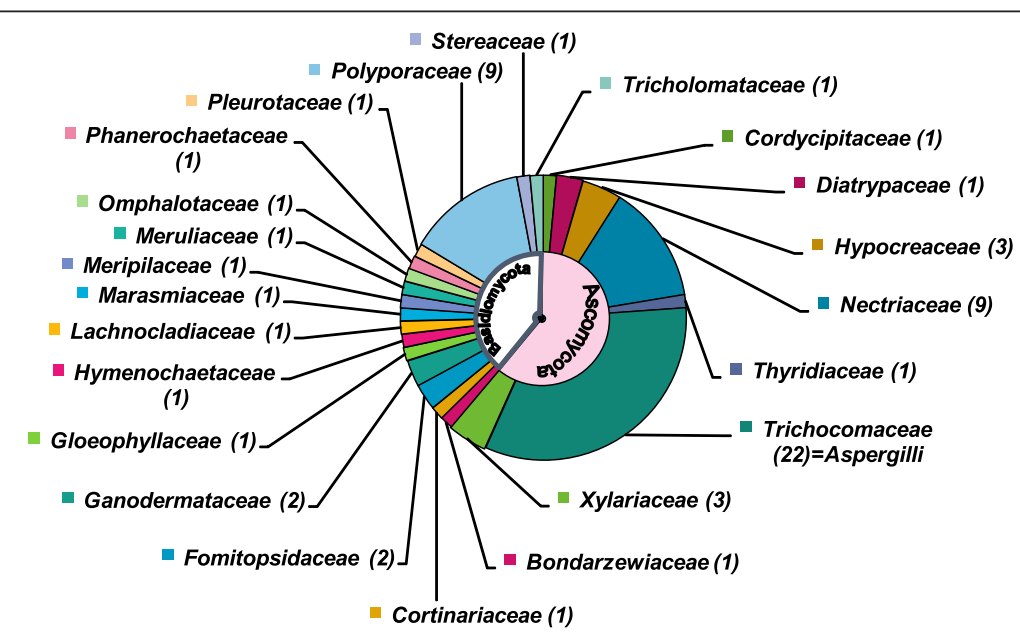

Figure 3 Repartition of the strains selected for the screening in the Ascomycota and Basidiomycota phyla. 40 strains of Ascomycota representing 6 families and 26 strains of Basidiomycota representing 16 families were screened. 
mean organic acids production. The supernatants of the higher producers were then analyzed separately and the identification of organic acids and ethanol was further studied using GC-MS.

Supernatants of the cultures were harvested by centrifugation and organic acids were directly derivatized, without ultrafiltration, using MCF as previously described [36], with some modifications. Briefly, $190 \mu \mathrm{L}$ of the supernatants were directly alkalinized with $10 \mu \mathrm{L} \mathrm{NaOH} 2.5 \mathrm{M}$ and derivatized by two consecutive additions of $20 \mu \mathrm{L}$ MCF. After derivatization, the methylated compounds were extracted with dichloromethane. GC-MS analysis of organic acids was performed with an Agilent $5973 \mathrm{~N}$ system, equipped with an Omegawax (Supelco, Bellefont, PA, USA), $30 \mathrm{~m} \times$ $250 \mu \mathrm{m}$ i.d. $\times 0,25 \mu \mathrm{m}$ thick films. The carrier gas was helium at $35 \mathrm{~cm} \cdot \mathrm{s}^{-1}$. The oven program temperature started at $40^{\circ} \mathrm{C}$ during $3 \mathrm{~min}$, then rose at $8^{\circ} \mathrm{C}$ per minute to $230^{\circ} \mathrm{C}$ and held at this temperature for $15 \mathrm{~min} .2 \mu \mathrm{L}$ of extract were injected in split injector port with split ratio of 10 . Mass spectra in the 29 to $400 \mathrm{~m} / \mathrm{z}$ range were recorded at a scanning speed of 2 scans. $\mathrm{s}^{-1}$ and an electronic ionization at $70 \mathrm{eV}$. Compounds were identified by matching compound mass spectra to the NIST library and using pure authentic chemical standards for each organic acid studied, derivatized using the same process as biological samples.

Ethanol concentration was determined in $2 \mathrm{~mL}$ supernatants by Head-space-GC-MS with addition of $0.4 \mathrm{~mL}$ of the internal standard $\mathrm{CD}_{3} \mathrm{OH}$ at $0.6 \mathrm{~g} . \mathrm{L}^{-1}$. A calibration curve was prepared with 201.8, 403.6 and $807.2 \mu \mathrm{g}$ of ethanol with $\mathrm{CD}_{3} \mathrm{OH}$ as internal standard as above. For GC we used the GC-MS QP2010 Shimadzu with capillary column Cp_wax_52cb $30 \mathrm{~m} \times 0.32 \mathrm{~mm} \times$ $0.5 \mu \mathrm{m}$ (Varian, Inc, Palo Alto, USA) equipped with an autosampler AOC5000. The sealed vials were placed at $50^{\circ} \mathrm{C}$ for $8 \mathrm{~min}$ with $500 \mathrm{rpm}$ shaking before $0.5 \mathrm{~mL}$ of the headspace were drawn out with a gas syringe heated at $60^{\circ} \mathrm{C}$ and injected with in a split injector with a split ratio of 10 . The carrier gas was helium at $35 \mathrm{~cm} \cdot \mathrm{s}^{-1}$ and oven temperature was isothermal at $50^{\circ} \mathrm{C}$. Mass detector conditions were: electronic impact ionization mode $(70 \mathrm{eV})$, temperature of source $200^{\circ} \mathrm{C}$ with data collected using SIM for selected ions $\mathrm{m} / \mathrm{z}$ 45/46 and 35/30 for ethanol and $\mathrm{CD}_{3} \mathrm{OH}$ respectively.

\section{Conclusion}

The potentiality of a wide panel of fungus for organic acids production has been studied in glucose based liquid media at acidic $\mathrm{pH}$ to take into account industrial up- and down-stream technical and economical issues. Strains were sorted in two clusters considering their organic acid and ethanol production at day 6 of incubation, showing that some strains, even from the same species, seem to have particular predispositions for some metabolites.
Among 26 Basidiomycota tested, only two: Postia stiptica (brown-rot) and Ganoderma weberianum (whiterot) produced oxalic acid. Ethanol is the common metabolite in the fungal kingdom, regardless the geographic origin of the strains, but with different extent depending on the strain. Although yeasts have very competitive ethanol productivity on simple sugars, our best ethanol producers may be good candidates for consolidated bioprocessing (CBP) of cellulosic biomass for second generation ethanol production.

Among the Ascomycota, Aspergilli clearly make a distinct cluster for their various and high concentration organic acid production; this illustrates the relevance of organic acids in the chemotaxonomy of Aspergilli. Some of these strains showed particular ability to produce malic, oxalic, gluconic and citric acids or ethanol at low $\mathrm{pH}$. This production could be further improved by genetic modifications. The high intra-specific variability in metabolite production stresses the importance of screenings for a good choice of studied strains.

This study provides a better knowledge of the capability of filamentous fungi to produce organic acids which should allow a greater exploitation of filamentous fungi in synthetic biology, metabolic studies and industrial exploitation of organic acids.

\section{Abbreviations \\ CIRM-CF: Fungal culture collection of the international centre of microbial resources; MCF: Methyl chloroformate.}

\section{Competing interests}

The authors declare that they have no competing interests.

\section{Authors' contribution}

NL participated in the design of the study and interpretation of data, carried out the experimental work and drafted the manuscript. CG designed, performed and analyzed the GC-MS analysis and helped drafting the manuscript. DN helped creating the figures and participated in the study design. NF, SC, IG, $\mathrm{AL}, \mathrm{SR}$ and JCS contributed in the conception of the study and interpretation of data and helped drafting the manuscript. All authors read and approved the final manuscrpt.

\section{Acknowledgements}

This work was supported by an Industrial Training and Research Agreement (CIFRE) and co-funded by the National Association of Research and Technology (ANRT). The authors want to thank Jean-Charles Martin (UMR-NORT), Catherine Defroost (UMR-NORT) and Marie-Pierre Forquin-Gomez (UMR-BCF) for their help in mass spectrometry. The authors are also grateful to Sabine Taussac (CIRM-CF) for her work with the strains authentification.

\section{Author details}

${ }^{1}$ INRA, UMR1163 Biotechnology of Filamentous Fungi, Marseille F-13288, France. ${ }^{2}$ Aix Marseille Université, UMR1163 Biotechnology of Filamentous Fungi, Marseille F-13288, France. ${ }^{3}$ ARD, Agro-Industry Research and Development, Pômacle F-51100, France. ${ }^{4}$ INRA, UMR 1260, « Nutrition, Obésité et Risque Thrombotique », Marseille F-13385, France. ${ }^{5}$ INSERM, UMR 1062, "Nutrition, Obésité et Risque Thrombotique », Marseille F-13385, France. ${ }^{6}$ Université d'Aix-Marseille, UMR 1260, «Nutrition, Obésité et Risque Thrombotique », Faculté de Médecine, Marseille F-13385, France. ${ }^{7}$ INRA, International Center for Microbial Resources collection-Filamentous fungi CIRM-CF, Marseille F-13288, France. ${ }^{8}$ Polytech' Marseille (ex ESIL), UMR 1163 BCF - INRA / AMU, 163 Avenue de Luminy CP 925, Marseille F-13288, France. 
Received: 3 April 2014 Accepted: 23 June 2014

Published online: 01 November 2014

\section{References}

1. Plassard C, Fransson P: Regulation of low-molecular weight organic acid production in fungi. Fungal Biol Rev 2009, 23:30-39.

2. Magnuson JK, Lasure LL: Organic acid production by filamentous fungi. In Adv fungal biotechnol ind agric med. Edited by Tkacz JS, Lange L. Boston, MA: Springer US; 2004:307-340.

3. Dutton MV, Evans CS: Oxalate production by fungi: its role in pathogenicity and ecology in the soil environment. Can J Microbiol 1996, 42:881-895.

4. Jones DL: Organic acids in the rhizosphere - a critical review. Plant Soil 1998, 205:25-44.

5. Tanaka N, Akamatsu Y, Hattori T, Shimada M: Effect of oxalic acid on the oxidative breakdown of cellulose by the Fenton reaction. Wood Res Bull Wood Res Inst Kyoto Univ 1994, 81:8-10.

6. Shimada M, Akamtsu Y, Tokimatsu T, Mii K, Hattori T: Possible biochemical roles of oxalic acid as a low molecular weight compound involved in brown-rot and white-rot wood decays. J Biotechnol 1997, 53:103-113.

7. Green F, Highley TL: Mechanism of brown-rot decay: paradigm or paradox. Int Biodeterior Biodegradation 1997, 39:113-124.

8. Espejo E, Agosin E: Production and degradation of oxalic acid by brown rot fungi. Appl Environ Microbiol 1991, 57:1980-6.

9. Ahonen-Jonnarth U, Van Hees PAW, Lundström US, Finlay RD: Organic acids produced by mycorrhizal Pinus sylvestris exposed to elevated aluminium and heavy metal concentrations. New Phytol 2000, 146:557-567.

10. Hastrup ACS, Green F, Lebow PK, Jensen B: Enzymatic oxalic acid regulation correlated with wood degradation in four brown-rot fungi. Int Biodeterior Biodegradation 2012, 75:109-114.

11. Mäkelä M, Galkin S, Hatakka A, Lundell T: Production of organic acids and oxalate decarboxylase in lignin-degrading white rot fungi. Enzyme Microb Technol 2002, 30:542-549.

12. Takao S: Organic acid production by Basidiomycetes: I. screening of acid-producing strains. Appl Microbiol 1965, 13:732-7.

13. Vanhees $P$, Jones $D$, Jentschke G, Godbold D: Organic acid concentrations in soil solution: effects of young coniferous trees and ectomycorrhizal fungi. Soil Biol Biochem 2005, 37:771-776.

14. Hofrichter M, Vares T, Kalsi M, Galkin S, Scheibner K, Fritsche W, Hatakka A: Production of manganese peroxidase and organic acids and mineralization of ${ }^{14} \mathrm{C}$-labelled lignin $\left({ }^{14} \mathrm{C}\right.$-DHP) during solid-state fermentation of wheat straw with the white rot fungus Nematoloma frowardii. Appl Environ Microbiol 1999, 65:1864-70.

15. Goodell B, Jellison J, Liu J, Daniel G, Paszczynski A, Fekete F, Krishnamurthy $S$, Jun L, Xu G: Low molecular weight chelators and phenolic compounds isolated from wood decay fungi and their role in the fungal biodegradation of wood. J Biotechnol 1997, 53:133-162.

16. Guggiari $M$, Bloque $R$, Aragno $M$, Verrecchia $E$, Job $D$, Junier $P$ : Experimental calcium-oxalate crystal production and dissolution by selected wood-rot fungi. Int Biodeterior Biodegradation 2011, 65:803-809.

17. Sauer M, Porro D, Mattanovich D, Branduardi P: Microbial production of organic acids: expanding the markets. Trends Biotechnol 2008, 26:100-8.

18. Li A, Punt P: Industrial production of organic acids by Fungi. In Appl Microb Eng. Edited by Gupta V, Schmill M, Mazutti M, Mäki M, Tuohy M. London: Taylor and Francis Group 2013; 2013:52-74.

19. Berrin J-G, Navarro D, Couturier M, Olivé C, Grisel S, Haon M, Taussac S, Lechat C, Courtecuisse R, Favel A, Coutinho PM, Lesage-Meessen L: Exploring the natural fungal biodiversity of tropical and temperate forests toward improvement of biomass conversion. Appl Environ Microbiol 2012, 78:6483-90.

20. Saeed A, Bhagabati N, Braisted J, Liang W, Sharov V, Howe E, Li J, Thiagarajan M, White J, Quackenbush J: TM4 microarray software suite. Methods Enzym 2006, 411:134-193.

21. Lee MY, Park HM, Son GH, Lee CH: Liquid chromatography-mass spectrometry-based chemotaxonomic classification of Aspergillus spp. and evaluation of the biological activity of its unique metabolite, neosartorin. J Microbiol Biotechnol 2013, 23:932-41.

22. Maehara T, Ichinose H, Furukawa T, Ogasawara W, Takabatake K, Kaneko S: Ethanol production from high cellulose concentration by the basidiomycete fungus Flammulina velutipes. Fungal Biol 2013, 117:220-6.
23. Mizuno R, Ichinose $H$, Maehara T, Takabatake $K$, Kaneko S: Properties of ethanol fermentation by Flammulina velutipes. Biosci Biotechnol Biochem 2009, 73:2240-5.

24. Singh A, Kumar P, Schügerl K: Bioconversion of cellulosic materials to ethanol by filamentous fungi. In Enzym prod from bact fungi plant cells: volume 45. Berlin/Heidelberg: Springer-Verlag; 1992:29-55. Advances in Biochemical Engineering/Biotechnology.

25. Ali S, Nugent B, Mullins E, Doohan F: Insights from the fungus Fusarium oxysporum foint to high affinity glucose transporters as targets for enhancing ethanol production from lignocellulose. PLoS One 2013, 8:e54701.

26. Christakopoulos P, Macris BJ, Kekos D: Direct fermentation of cellulose to ethanol by Fusarium oxysporum. Enzyme Microb Technol 1989, 11:236-239.

27. Kubicek CP, Schreferl-Kunar G, Wöhrer W, Röhr M: Evidence for a cytoplasmic pathway of oxalate biosynthesis in Aspergillus niger. Appl Environ Microbiol 1988, 54:633-7.

28. Gharieb MM, Gadd GM: Influence of nitrogen source on the solubilization of natural gypsum $\left(\mathrm{CaSO}_{4} \cdot 2 \mathrm{H}_{2} \mathrm{O}\right)$ and the formation of calcium oxalate by different oxalic and citric acid-producing fungi. Mycol Res 1999, 103:473-481.

29. Mandal S, Banerjee P: Oxalic acid production by Aspergillus niger: influence of hydrogen ion concentration and nitrogen source. Res $J$ Microbiol 2010, 5:810-827.

30. Skory CD, Freer SN, Bothast R: Screening for ethanol-producing filamentous fungi. Biotechnol Lett 1997, 19:203-206.

31. Ingledew W: Yeasts: physiology, nutrition and ethanol production. In Alcohol text book 5th edn. Edited by Ingledew W, Kelsall D, Austin G, Kluspies C. Nottingham: Nottingham University Press; 2009:101-114.

32. Sedlak M, Ho NWY: Production of ethanol from cellulosic biomass hydrolysates using genetically engineered Saccharomyces yeast capable of cofermenting glucose and xylose. Appl Biochem Biotechnol 2004, 113-116:403-16.

33. Hasunuma T, Okazaki F, Okai N, Hara KY, Ishii J, Kondo A: A review of enzymes and microbes for lignocellulosic biorefinery and the possibility of their application to consolidated bioprocessing technology. Bioresour Technol 2013, 135:513-22.

34. Kubicek $C P$, Punt $P$, Visser J: Production of organic acids by filamentous fungi. In Ind appl. Edited by Hofrichter M. Heidelberg: Springer Berlin Heidelberg; 2011, 10:215-234

35. Tatum E, Barratt R, Fries N, Bonner D: Biochemical mutant strains of neurospora produced by physical and chemical treatment. Am J Bot 1950, 38-46.

36. Villas-Bôas SG, Delicado DG, Akesson M, Nielsen J: Simultaneous analysis of amino and nonamino organic acids as methyl chloroformate derivatives using gas chromatography-mass spectrometry. Anal Biochem 2003, 322:134-8.

\section{doi:10.1186/s40694-014-0001-z}

Cite this article as: Liaud et al:: Exploring fungal biodiversity: organic acid production by 66 strains of filamentous fungi. Fungal Biology and Biotechnology 2014 1:1.

\section{Submit your next manuscript to BioMed Central and take full advantage of:}

- Convenient online submission

- Thorough peer review

- No space constraints or color figure charges

- Immediate publication on acceptance

- Inclusion in PubMed, CAS, Scopus and Google Scholar

- Research which is freely available for redistribution 